\title{
Hydrogen Retention in Tungsten Materials Studied by Laser Induced Desorption
}

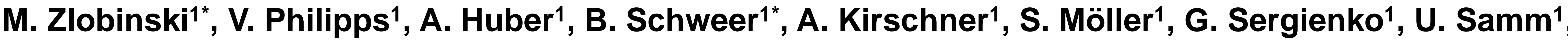 \\ M. H. J. 't Hoen ${ }^{2}$, A. Manhard 3 , K. Schmid ${ }^{3}$ and the TEXTOR Team 1
}

1 Institute of Energy and Climate Research - Plasma Physics, Forschungszentrum Jülich GmbH, Association EURATOM-FZJ,

Partner in the Trilateral Euregio Cluster, D-52425 Jülich, Germany

${ }^{2}$ Dutch Institute for Fundamental Energy Research (DIFFER), EURATOM-FOM, NL-3439 MN Nieuwegein, The Netherlands ${ }^{3}$ Max-Planck-Institut für Plasmaphysik, EURATOM-Association, D-85748 Garching, Germany

\section{Introduction}

Tritium retention in plasma facing components (PFCs) due to plasma wall interactions is one of the most critical safety issues for present R\&D. spectroscopy.

\section{Laboratory:}

spatial resolution: $3 \mathrm{~mm}$ development of standard laser pulse at the $W$ target surface

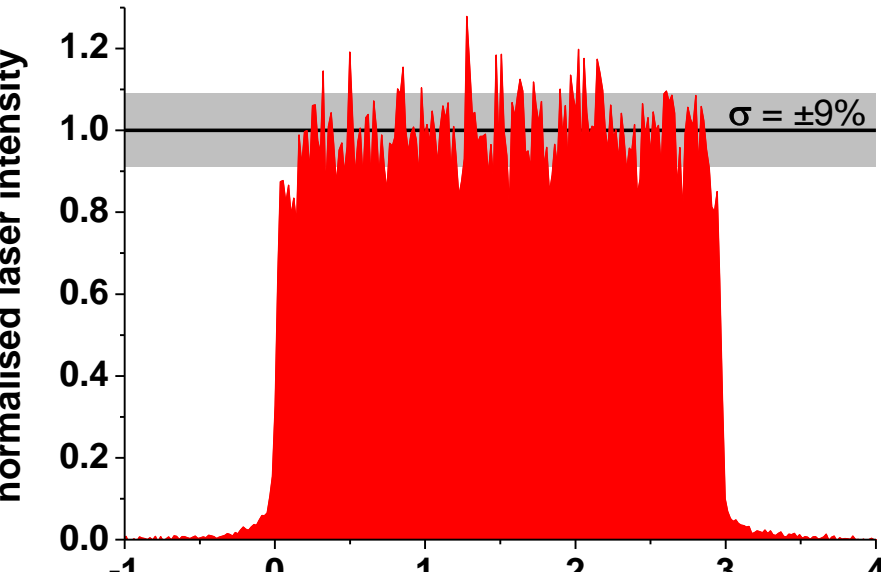
RF glow discharge ITER and future fusion devices. Tungsten is foreseen as PFC material in the divertor of ITER and the most promising candidate of PFCs in future reactors. Its fuel retention behaviour is subject of

In this work the retention of fuel (deuterium) in bulk tungsten has been studied applying laser induced desorption (LID). This method allows the local measurement of hydrogen isotopes and is also proposed for in situ diagnostic at ITER to monitor tritium retention.

Trapping of hydrogen in tungsten is strongly dependent on material properties and temperature during plasma exposure. Both effects can influence the results obtained by laser induced desorption

\section{Diagnostic Method}

Laser Induced Desorption with Quadrupole Mass Spectrometer LID: Nd:YAG laser: $\lambda=1064 \mathrm{~nm}, \mathrm{E} \leq 40 \mathrm{~J}, \mathrm{t}_{\mathrm{puse}} \leq 3 \mathrm{~ms}$

absorbed intensity: $P / A \leq 2 \mathrm{GW} / \mathrm{m}^{2}, \mathrm{f}=6 \mathrm{~cm}$ focussing lens

QMS: scan $1-50$ amu in $1 \mathrm{~s}$, pressure calibration in $\mathrm{H}_{2}, \mathrm{D}_{2}, \mathrm{CH}_{4}, \mathrm{CD}_{4}$, TEXTOR: $\quad$ Laser Induced Desorption Spectroscopy

LID: Nd:YAG laser: $\lambda=1064 \mathrm{~nm}, \mathrm{E} \leq 40 \mathrm{~J}, \mathrm{t}_{\text {pulse }} \leq 3 \mathrm{~ms}$,

absorbed intensity: $P / A \leq 500 \mathrm{MW} / \mathrm{m}^{2}, \mathrm{f}=30 \mathrm{~cm}$ focussing lens LIDS: optical spectroscopy of Balmer Alpha lines $\left(\mathrm{H}_{\alpha}\right)$

spatial distribution and temporal LID-QMS experimental set-up in laboratory
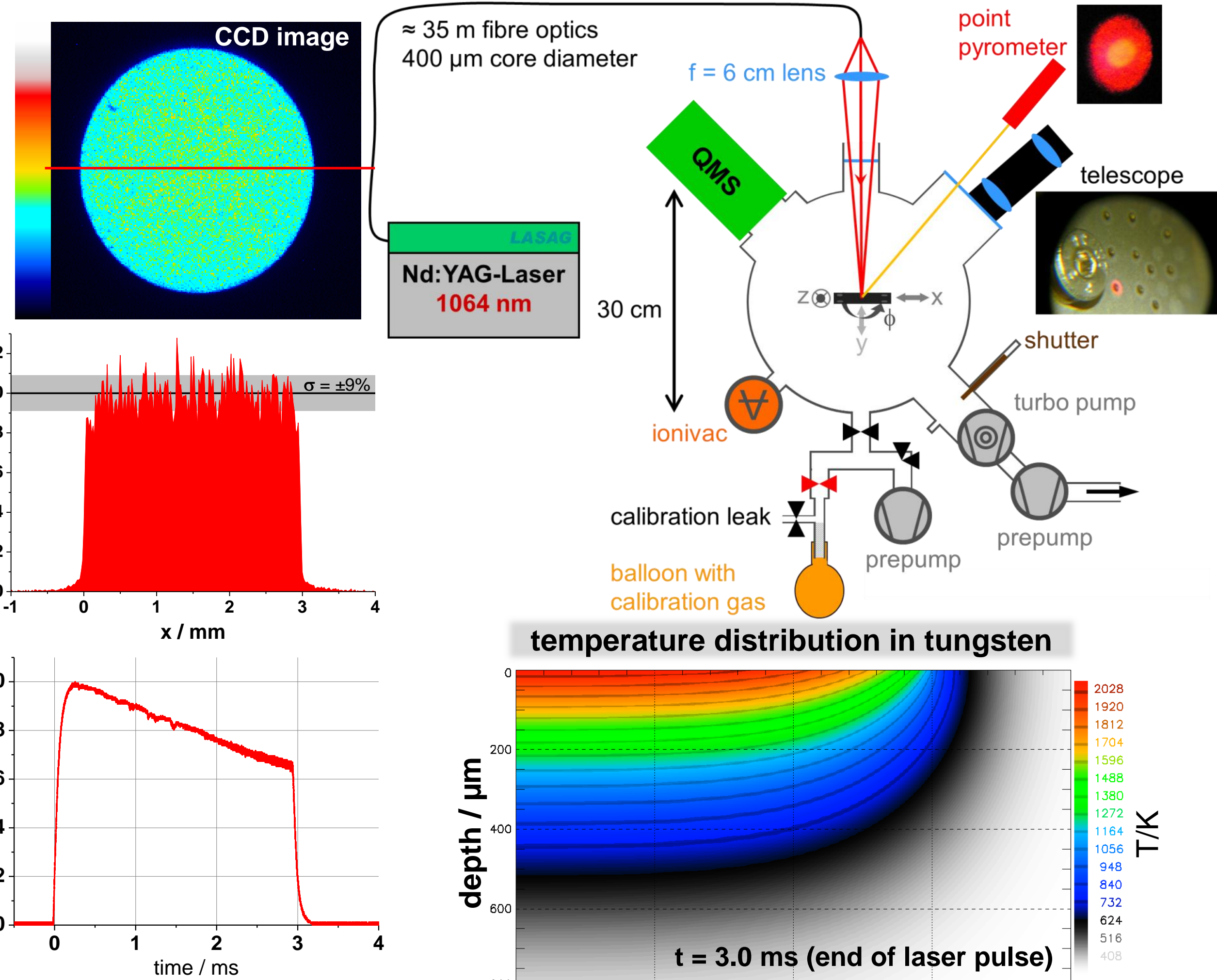

radius $/ \mathrm{mm}$

\section{Glow Discharge Exposure}

unpolished Goodfellow tungsten, annealed at $1273 \mathrm{~K}$ for $>1$ hour wiux: $2.8 \times 10^{19} \mathrm{D} / \mathrm{m}^{2} \mathrm{~s}, \mathrm{~T}_{\text {expo }}=533 \mathrm{~K}$

fluence: $2 \times 10^{23} \mathrm{D} / \mathrm{m}^{2}$ with $2 \mathrm{~h}$ exposure time

twin sample: $7.35 \times 10^{19} \mathrm{D} / \mathrm{m}^{2}$ (TDS) after $\mathbf{D}_{2}{ }^{+}$exposure in

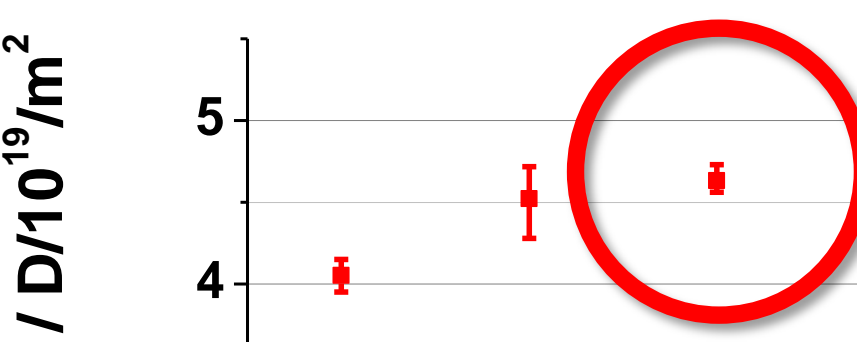

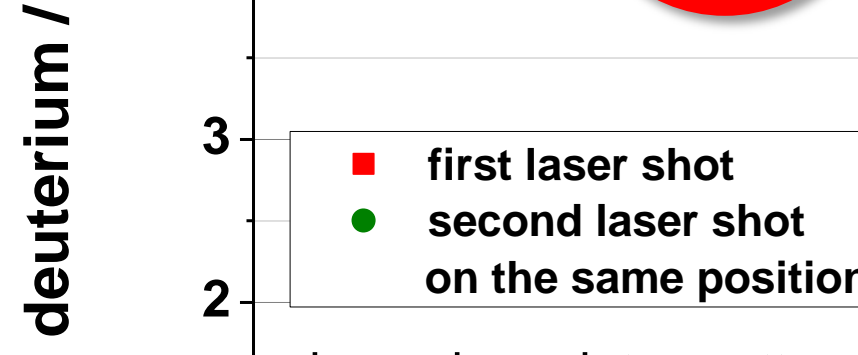

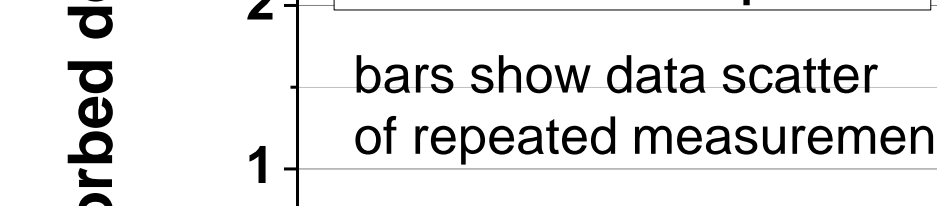

laser parameter optimization on homogenously loaded $\mathrm{W}$ by glow discharge

pulse length variation, but keeping the heat flux factor

$\sqrt{t}=\frac{P}{A} \sqrt{t}=\frac{E}{A \sqrt{t}}$ constant by energy ms adaptation

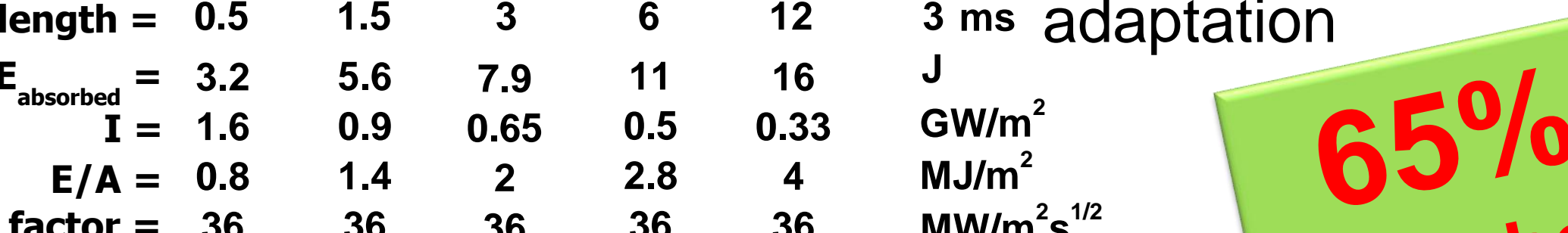
desorbed

short laser pulses $>$ time for hydrogen diffusion short $>$ low desorption

too long pulses $>$ lateral heat diffusion

a) reduced maximum temperature low desorption

b) fuzzy temperature profile fuzzy desorption volume

partial overlapping of neighbouring desorption volumes *m.zlobinski@fz-juelich.de,b.schweer@fz-juelich.de

\section{Results}

\section{TEXTOR Tokamak Plasma Exposure}

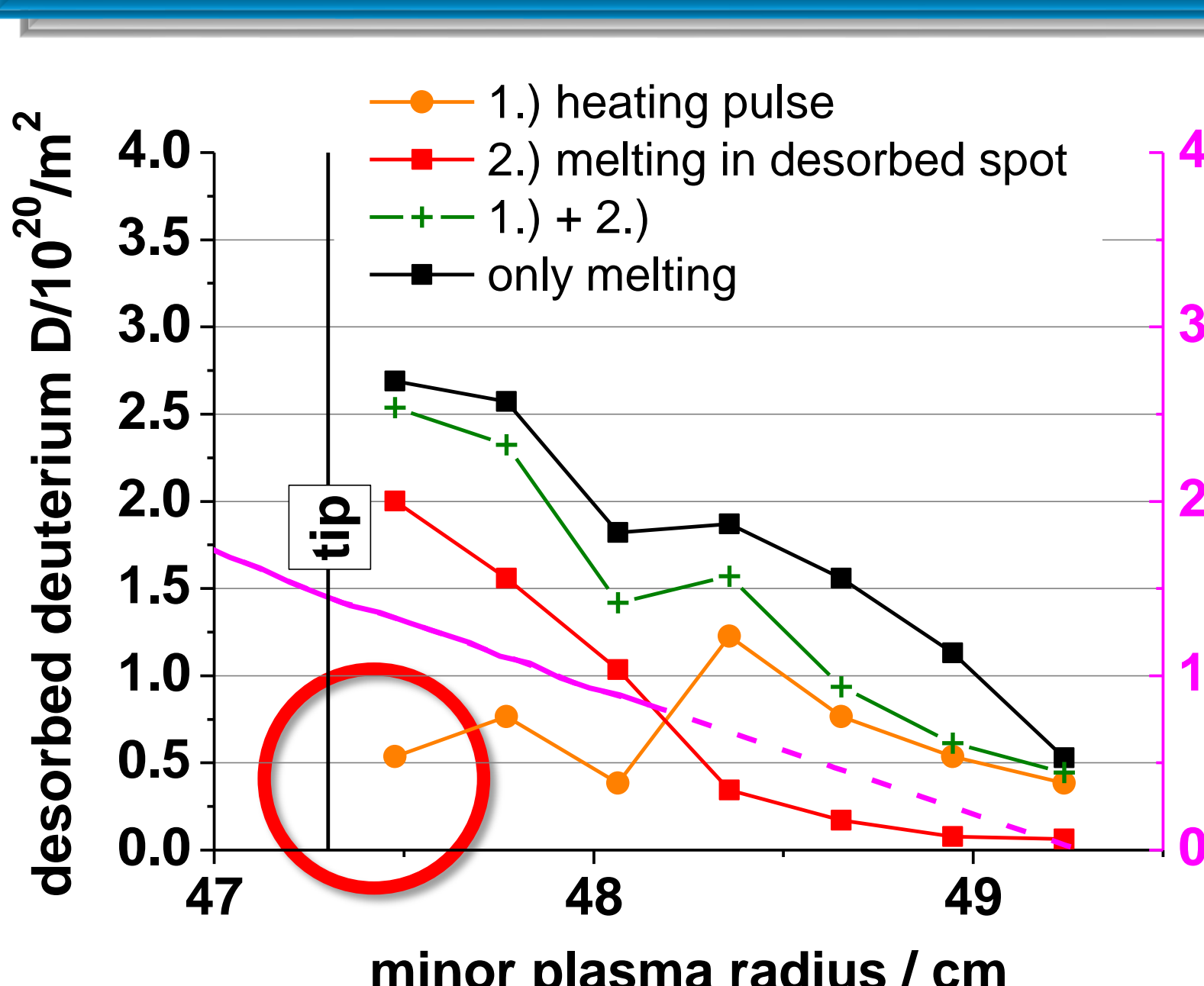

Melting pulse after heating pulse $p$

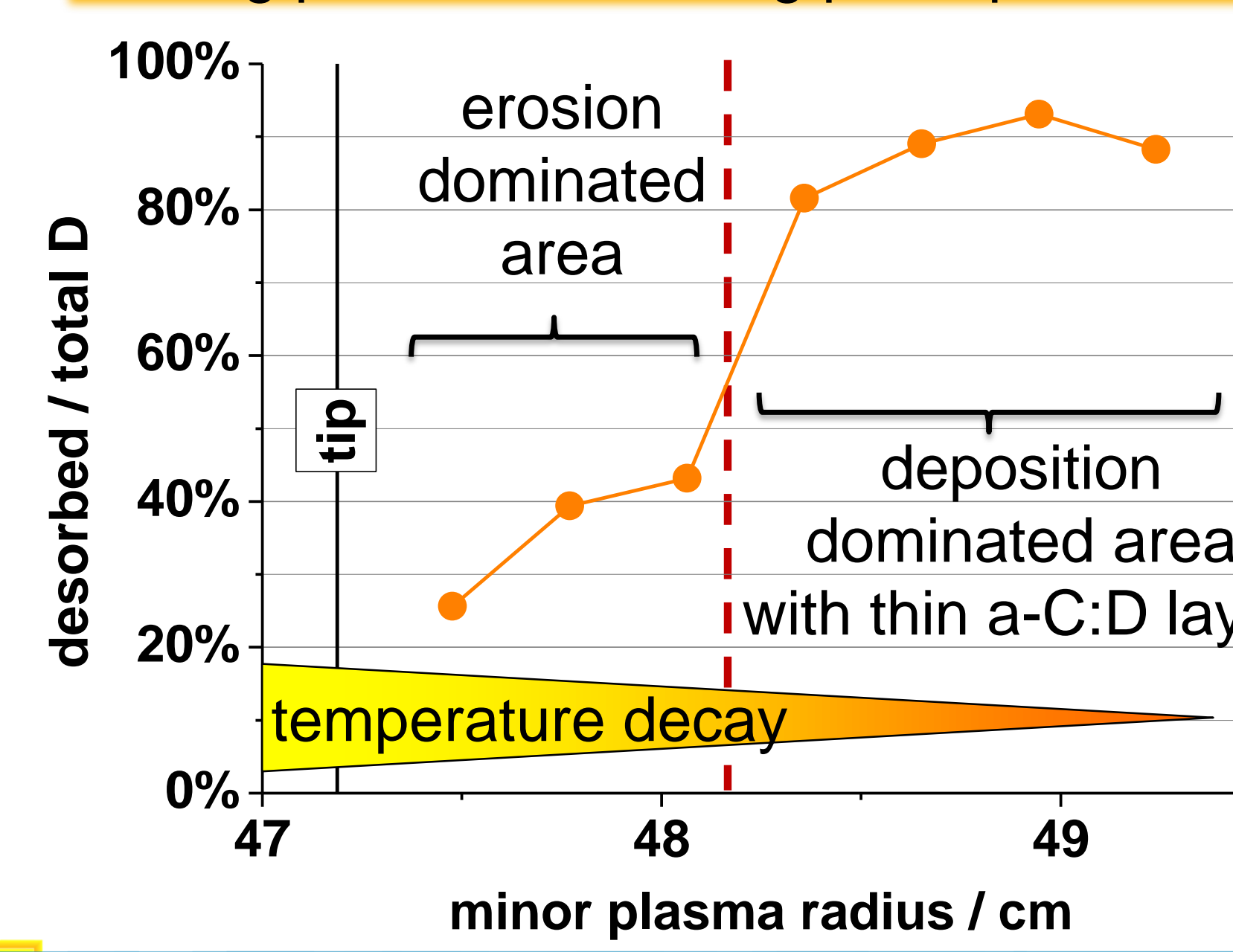
hydrocarbon layers on diffusion into the $\mathrm{W}$ bulk diffusion into the $W$ bulk
because $D$ implantation zone is now in the layer

Combination of heating and melting pulses

identifies areas with different

\section{High Flux Exposure (Pilot-PSI)}

\section{polished Goodfellow tun
high flux: $2 \times 10^{24} \mathrm{D} / \mathrm{m}^{2} \mathrm{~s}$}

fluence: $2 \times 10^{25} \mathrm{D} / \mathrm{m}^{2}$ with 10 s exposure time

$T_{\text {max }}=500-580 \mathrm{~K}$, temperature profile according to beam profile direct water cooling

$1.2 \mathrm{eV} \mathrm{D}, 3.7 \times 10^{20} / \mathrm{m}^{2}$ with additional $-55 \mathrm{~V}$ biasing

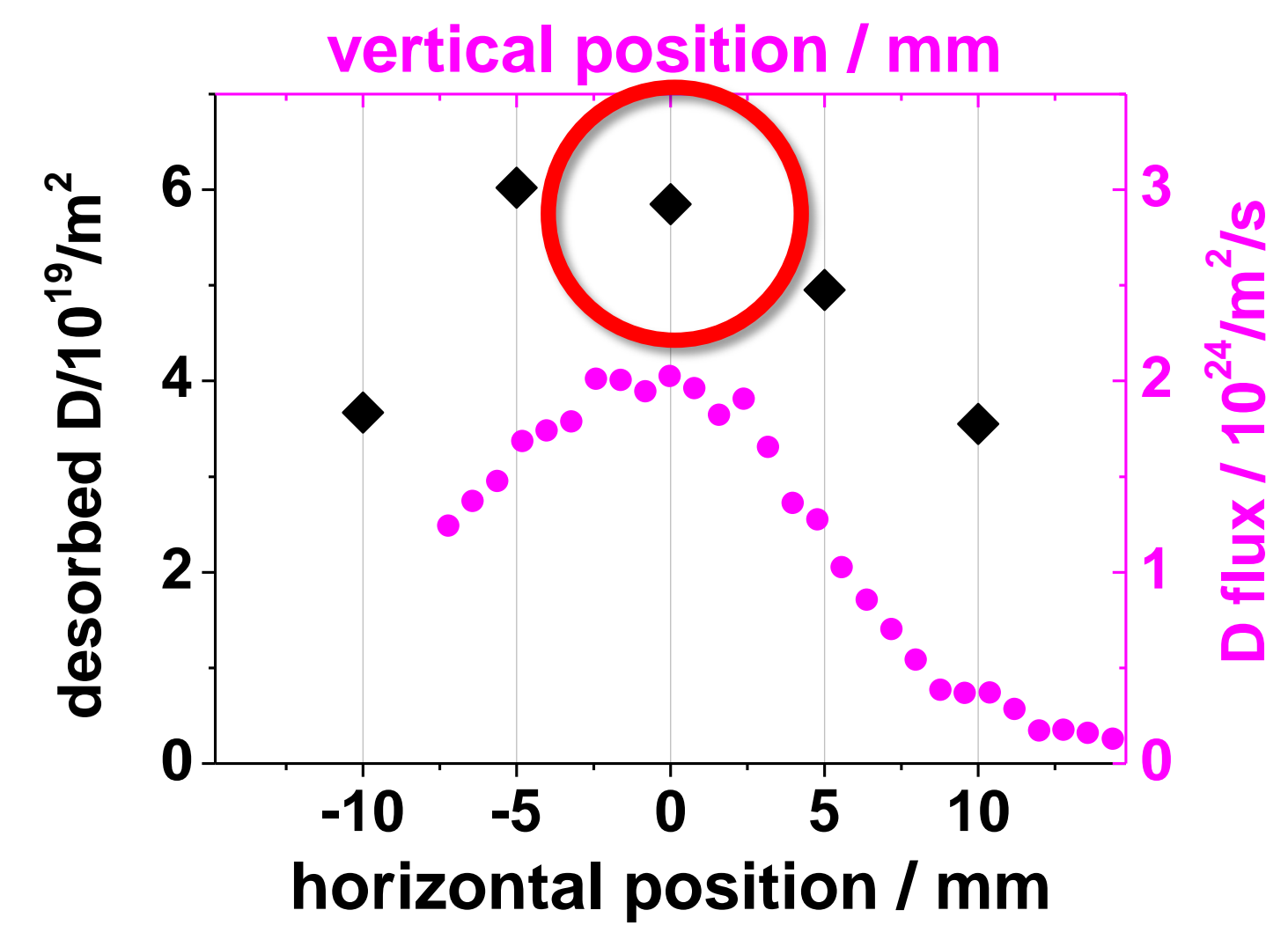

Similar fluence as in TEXTOR, yields similar amount of desorbed $\mathrm{D}$ by standard heating pulse.

Horizontal plasma maximum shift to the left induced by horizontal position / $\mathrm{mm}$ biasing is visible in $\mathrm{D}$ inventory.

\section{ECR Plasma Exposure}

\section{unpolished Plansee-tungsten, annealed at $1200 \mathrm{~K}$ for 1 hour} low flux: $10^{20} \mathrm{D} / \mathrm{m}^{2} \mathrm{~s}$ at $370 \mathrm{~K}$

deuterium inventory: TDS: $7.5 \times 10^{20} \mathrm{D} / \mathrm{m}^{2}$

luence: $6 \times 10^{24} \mathrm{D} / \mathrm{m}^{2}$ with $18 \mathrm{~h}$ exposure time $91 \%$ ECR heated plasma with $38 \mathrm{eV} / \mathrm{D}$

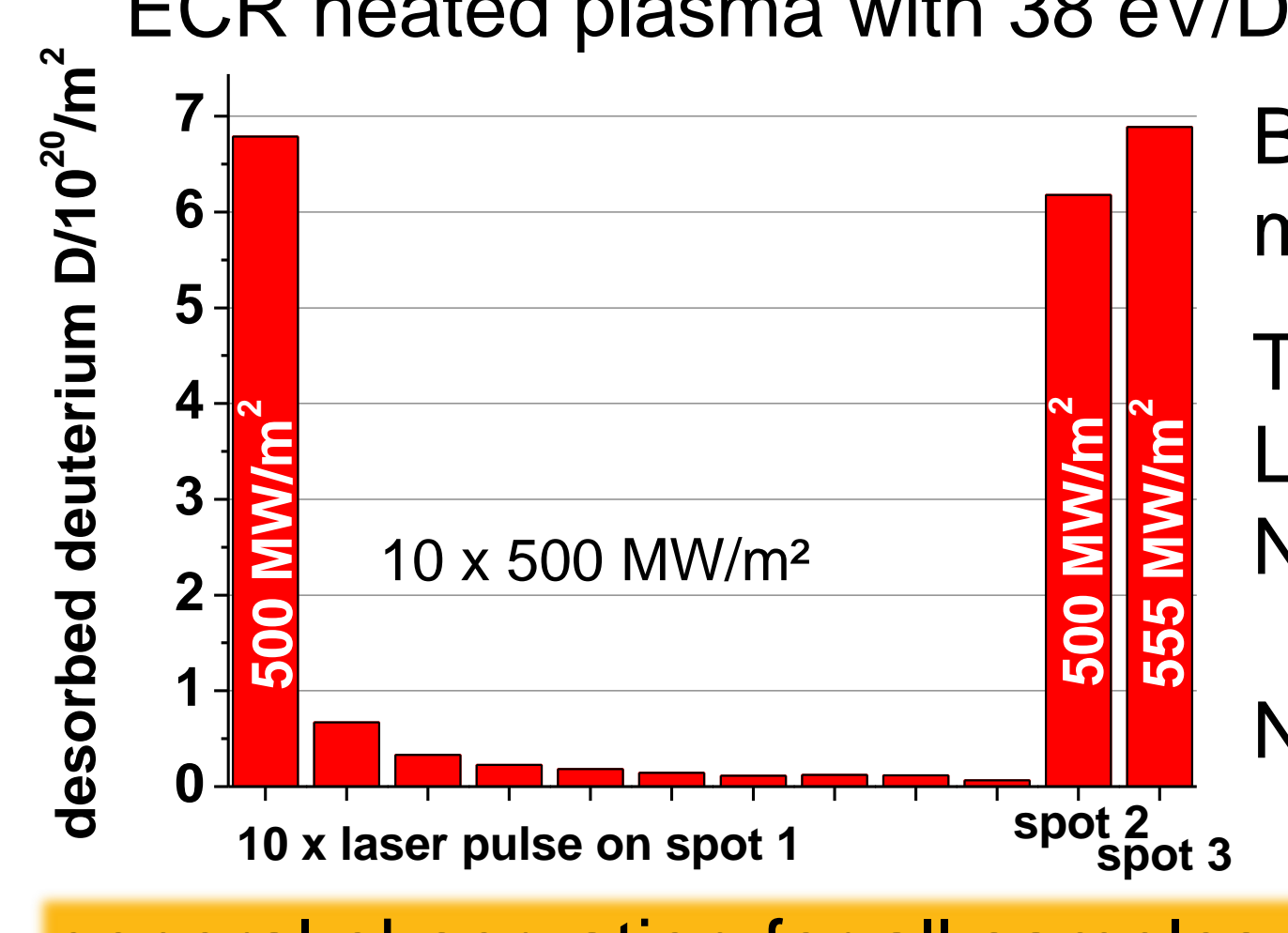

methods:

TDS: $7.5 \times 10^{20} \mathrm{D} / \mathrm{m}^{2}$

ID: $6.8 \times 10^{20} \mathrm{D} / \mathrm{m}^{2}$

NRA up to $12 \mu \mathrm{m}$ (with

$5.5 \times 10^{20} \mathrm{D} / \mathrm{m}^{2}$
NRA up to $7 \mu \mathrm{m}$ (with

$$
\begin{aligned}
& 4.1 \times 10^{20} \mathrm{D} / \mathrm{m}^{2} \\
& \text { up to } 7 \mu \mathrm{m} \text { (with }
\end{aligned}
$$

general observation for all samples: Repetitive standard heating pulses on one position yield $<10 \%$ of first pulse signal due to lateral and perpendicular D diffusion into the desorption volume.

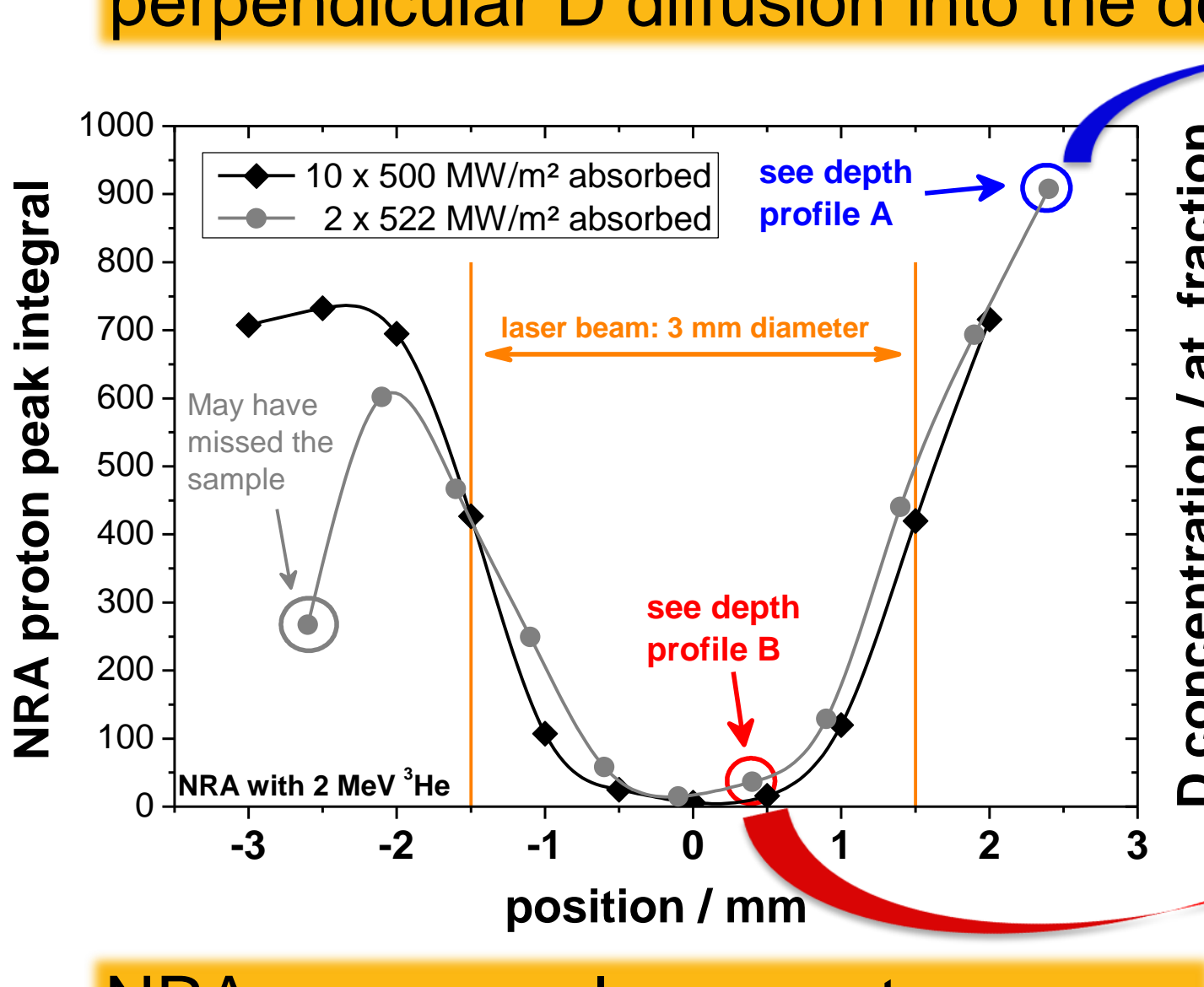

NRA scan over laser spots qualitatively shows the lateral depletion in the first $7 \mu \mathrm{m}$

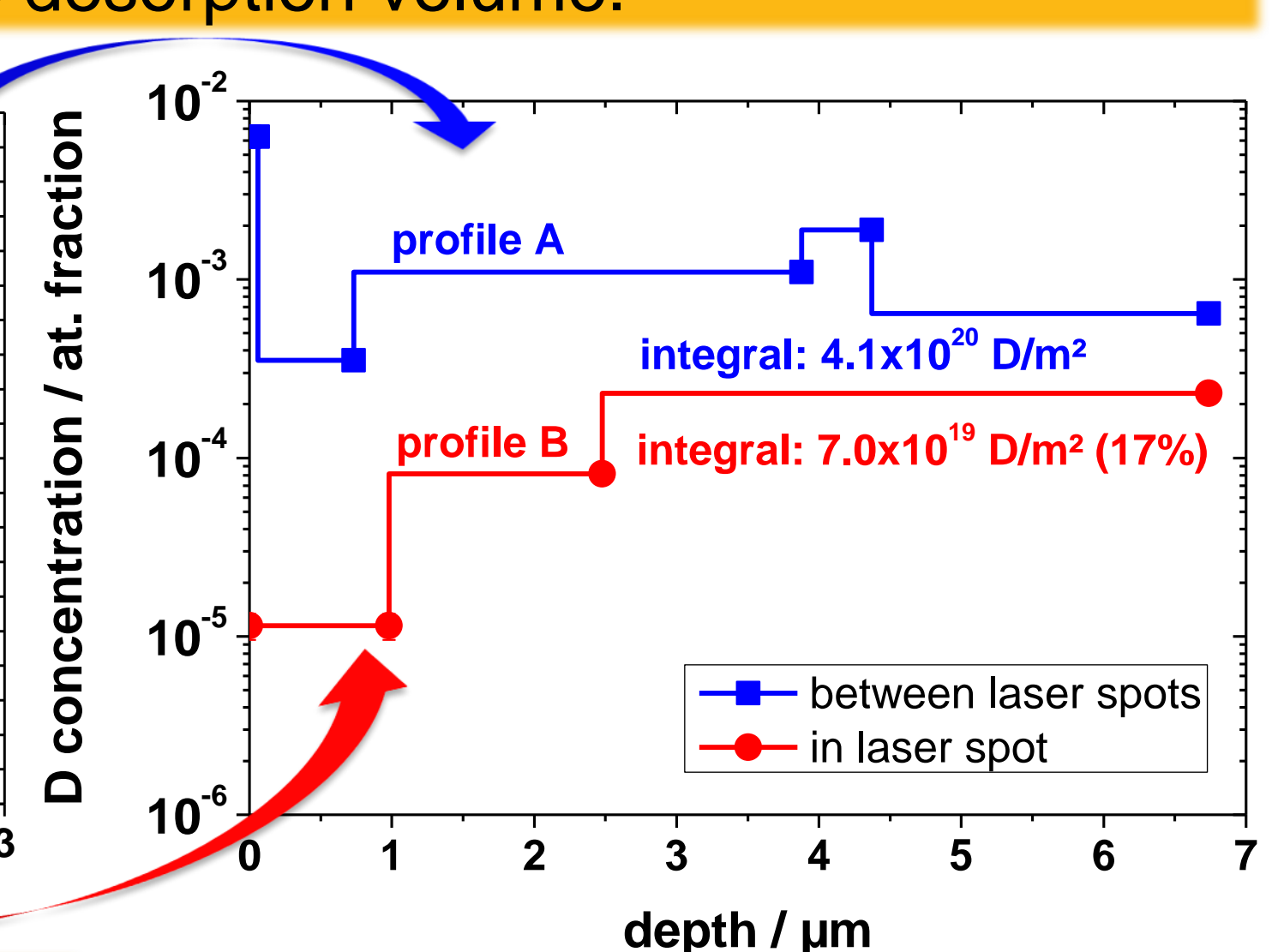

NRA depth profiles quantitatively prove $>83 \%$ desorption in first $7 \mu \mathrm{m}$ and decrease of surface concentration by factor 1000 Compare with diffusion modeling detection (QMS)

Loading conditions:

$370 \mathrm{~K} \leq \mathrm{T}_{\mathrm{w}} \leq 1500 \mathrm{~K}$

fluence: $2 \times 10^{23} \mathrm{D} / \mathrm{m}^{2} \leq \Gamma \leq 2 \times 10^{25} \mathrm{D} / \mathrm{m}^{2}$

Laser desorption (single heating pulse) temperature down to $\sim 20 \%$

Reasons: on traps with higher binding energy modeling shows: Stronger trapping and deeper deuterium start profile reduce laser desorption.

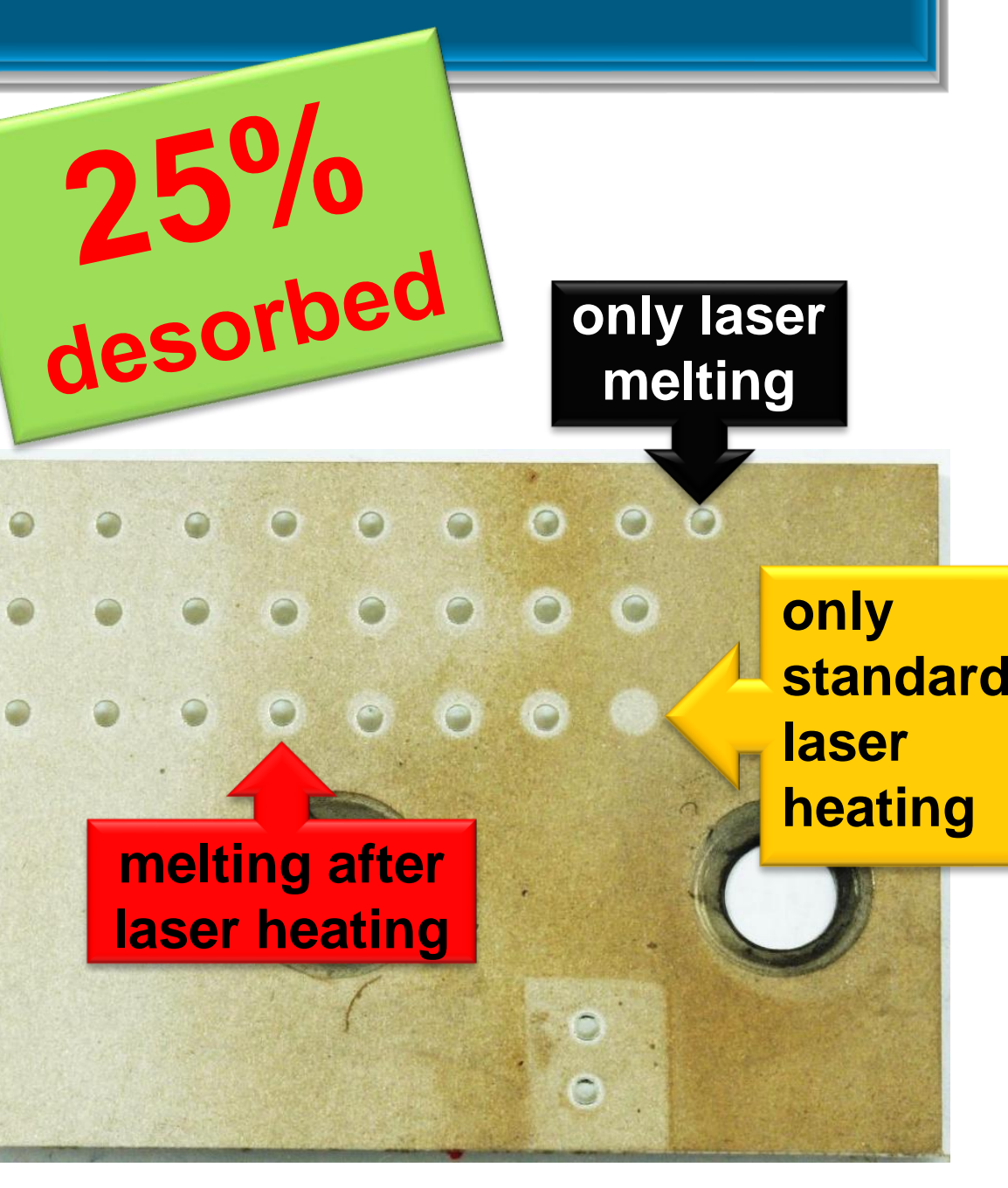

\section{Summary}

Aim: Measurement of hydrogen isotopes in tungsten by spot laser heating and plasma spectroscopy and/or mass spectroscopic

$\rightarrow$ in situ hydrogen monitoring during plasma operation

This work: Laser induced desorption and QMS

> $90 \%$ of fuel from a-C:H layers on W, C, CFC and from bulk - max $83 \%$ from bulk W, for low $\mathrm{T}(\approx 450 \mathrm{~K}$, Plansee materia) decrease of released hydrogen with increasing loading

deep diffusion of part of $\mathrm{H}$ in the material for high $\mathrm{T}_{W}$ or long different material properties with increased hydrogen storage

local spot melting releases all stored fuel within depth of $\sim 100 \mu \mathrm{m}$ Strategy: frequent desorption of the same monitoring spots on first wall before the fuel is out of laser desorption range

Results in context to literature and community values:

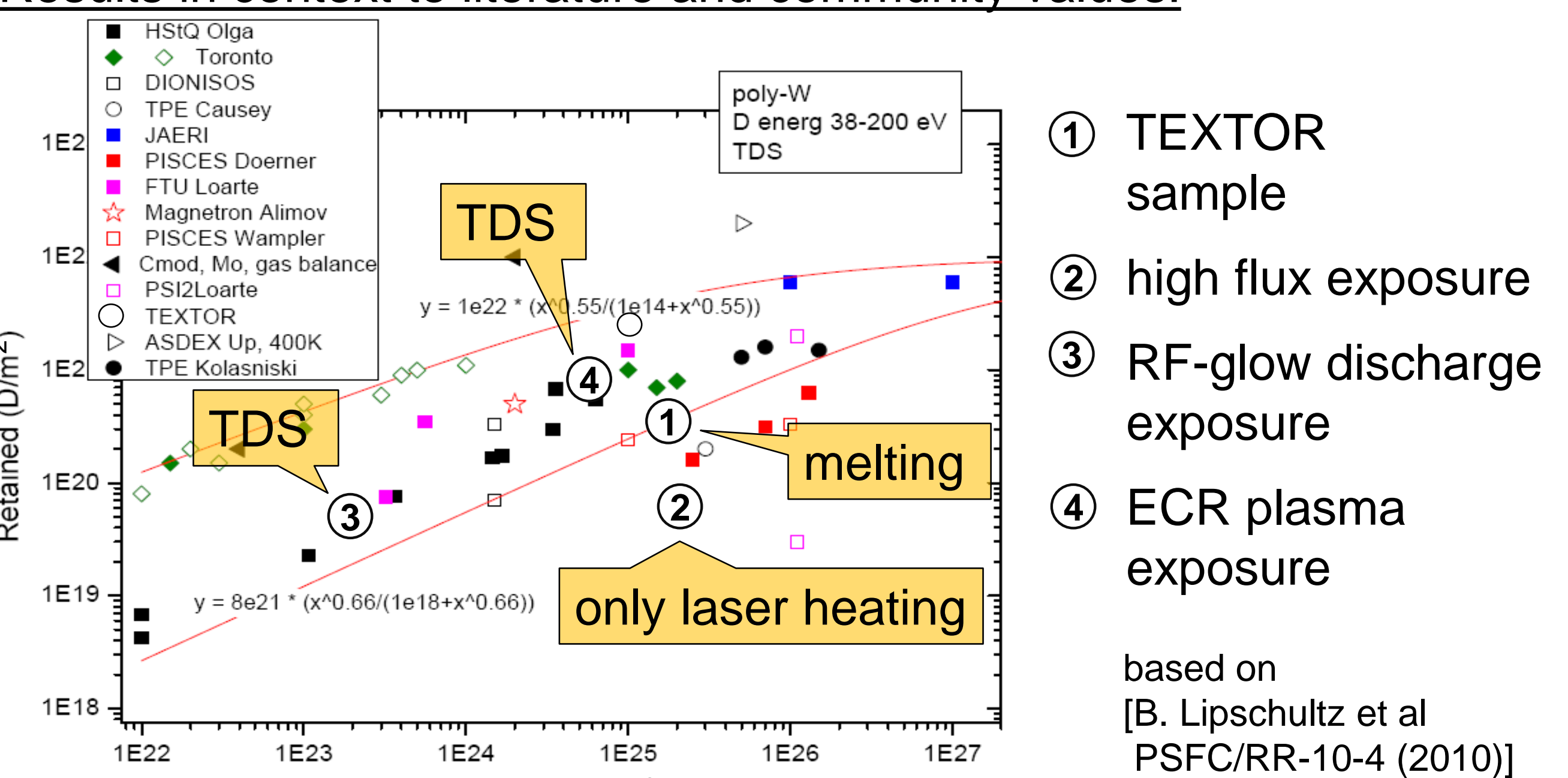

\section{Laser Heating Simulation}

1D-code for diffusion of heat and particles: TMAP7 [G. R. Longhurst et al,

assumed initial $\mathrm{D}$ profile up to $9 \mu \mathrm{m}$ with $3 \mu \mathrm{m}$ decay length performing standard heating pulse $\left(500 \mathrm{MW} / \mathrm{m}^{2}, 3 \mathrm{~ms}\right)$

case 1: only interstitial sites as "traps"

reduce laser desorption.

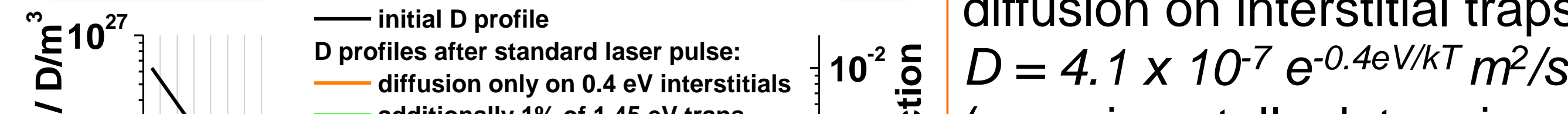

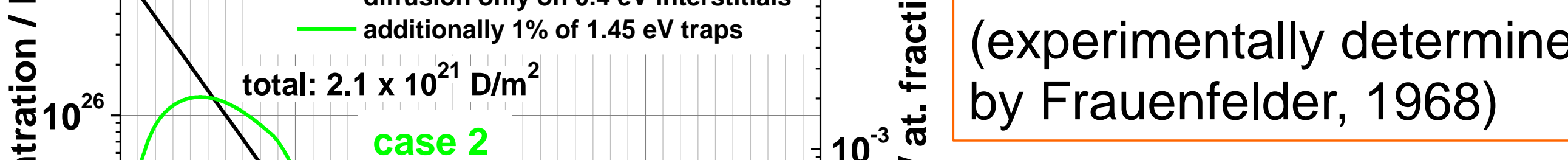

Forschungszentrum Jülich | Institute of Energy and Climate Research - Plasma Physics | Association EURATOM-FZJ 